\title{
O Ensino de Farmácia
}

Iracema Joana Salim Estefan*

* Farmacêutica - Assesșora

\section{INTRODUÇÃO}

Na história antiga e contemporânea da profissão de Farmácia temos testemunhado a dualidade na ênfase profissional sobre os medicamentos, os produtos e o interesse comercial que lhe corresponde. Inúmeros estudos e publicações manifestam o conflito bem como o sinergismo provocados por esta dualidade. Apesar das implicaçōes teóricas e práticas das características da Farmácia, é uma realidade o fato de que a profissão farmacêutica, mais que qualquer outra profissão da área da saúde, entrelaça interesses profissionais com interesses comerciais.

A profissão farmacêutica não ê uma ilha em si mesma. A natureza de seu exercício está profundamente imbricada na malha de normas legais, infra-estrutura política, aspectos empresariais e inter-relações profissionais. Assim, pode-se afirmar que o exercício da Farmácia se processa em um entorno complexo, às vezes favorável, outras vezes hostil.

Não obstante, a sobrevivência da profissão farmacêutica deriva de seu entorno, não de maneira distinta a dos modelos biológicos e físicos que descrevem a natureza de seu conteúdo. Assim, vemos hoje na Farmácia uma necessidade urgente de compreender e assimilar a essência de sua própria identidade profissional bem como do entorno mais amplo de onde emana sua existência. Se de um lado necessitamos compreender essas variáveis para poder controlá-las, por outra parte, devemos ter pleno conhecimento dos fatores externos, ou seja, aquelas variáveis que não estão sob nosso controle e que desempenham um importante papel na configuração de nossa profissão. Esta compreensão nos situará em um contexto adequado e nos ajudará a planejar e compreender nosso futuro.

Faz-se necessário, pois, buscar saber o que é a Farmácia, a quem serve, como o faz, e em que contexto.

A Farmácia é um sistema de conhecimento que tem como característica fundamental o estudo dos medicamentos em todos os seus aspectos.

Em 1966 Pourchet Campos $^{8}$ integra ao medicamento o alimento e o tóxico e conceitua Farmácia como sendo o "conhecimento amplo e pleno das substâncias que, direta ou indiretamente, tem significado para a saúde".

No estudo de Millis, PHARMACISTS FOR THE FUTU$\mathrm{RE}^{7}$, a Farmácia é conceituada como um serviço de saúde, posto que a única razão para pesquisar, produzir, distribuir, prescrever e dispensar medicamentos é que através dos mesmos se podem produzir efeitos benéficos na saúde da população, curando, prevenindo, controlando as doenças e reduzindo o sofrimento humano.

Cadernos de Saúde Pública, R.J., 2 (4): 511-532, out/dez, 1986 
O sistema Farmácia tem, portanto, como escopo o estudo do fármaco-medicamento em todos os seus aspectos, quer sejam tecnológicos quer os decorrentes da passagem dos medicamentos de uma dimensão técnica para uma dimensão clínica.

Entretanto, como conseqüência da evolução da Farmácia e por força de um "curriculum" extremamente eclético, outras áreas como as análises clínicas e toxicológicas e a de alimentos foram incorporadas pela profissão. Estas áreas representam hoje, legítimas conquistas da Farmácia, avaliadas pela sociedade, através dos serviços prestados, e muito embora não sendo atividades privativas, deverão ser aprimoradas e preservadas no conjunto das ciências farmacêuticas.

\section{O ÂMBITO PROFISSIONAL}

O exercício da profissão farmacêutica tem respaldo em diplomas legais sendo suas atribuições divididas em privativas e não-privativas.

O Decreto Federal no 85.878 de 07 de abril de 1981, estabeleceu normas para a execução da Lei 3.820 de 11 de novembro de 1960 , sobre o exerć́cio da profissão farmacêutica, fixando as atribuições profissionais do farmacêutico em:

a) Privativas

- Magistério superior (mat. privativas constantes, currículo de farmácia);

- Perícia Técnica Legal;

- Fiscalização técnica de empresas farmacêuticas;

- Fiscalização profissional;

- Farmacotécnica prescricional humana;

- Pesquisa e Planejamento de fármacos;

- Dispensação farmacêutica (pública, hospitalar, privada);

- Indústria de especialidades farmacêuticas;

- Cosméticos com indicação terapêutica;

- Produção e dispensação de fitoterápicos.

b) Não Privativas

- Indústria de insumos para fins farmacêuticos; cos;

- Indústria de insumos bioquímicos para fins farmacêuti-

- Fabrico de produtos higiênicos e cosméticos sem indicação farmacêutica;

- Indústria de produtos biológicos;

- Bromatologia e química bromatológica;

- Tratamento de água;

- Análises clínicas para fins clínicos;

- Análises químicas para fins industriais;

- Fábrico de produtos farmacêuticos para fins veterinários;

- Indústria de extratos opoterápicos;

- Indústria de raticidas, inseticidas e congêneres.

O ENSINO DE FARMÁCIA NO BRASIL

Existem hoje 35 estabelecimentos que ministram ensino superior de Farmácia a nível de graduação. Conforme pode 
ser visto na Tabela I e II estão distribuídas por todas as regiões do país, havendo uma maior concentração delas nas regiões mais desenvolvidas.

Do ponto de vista da dependência Administrativa Financeira (TABELA III), a maioria das Escolas ou Faculdades de Farmácia são Federais, tendo ocorrido um aumento substancial de estabelecimentos privados, nos altimos 6 anos localizados sobretudo no Estado de São Paulo.

\section{TABELA I}

Instituições que mantem Ensino Farmacêutico por Região Instituição Mantenedora e número de vagas

\begin{tabular}{|c|c|c|}
\hline REGIÄO & INSTITUIÇÃO & $\begin{array}{l}\text { No DE } \\
\text { VAGAS }\end{array}$ \\
\hline $\begin{array}{l}\text { NORTE } \\
\text { 1. Curso de Farmácia - MANAUS } \\
\text { 2. Curso de Farmácia - BELÉM }\end{array}$ & $\begin{array}{l}\text { Universidade Federal do Amazonas } \\
\text { Universidade Federal do Pará }\end{array}$ & $\begin{array}{l}30 \\
60\end{array}$ \\
\hline TOTAL & & 90 \\
\hline $\begin{array}{l}\text { NORDESTE } \\
\text { 3. Curso de Farmácia - SÃO LUIZ } \\
\text { 4. Curso de Farmácia - FORTALEZA } \\
\text { 5. Curso de Farmácia - NATAL } \\
\text { 6. Curso de Farmácia - CAMPINA } \\
\text { GRANDE } \\
\text { 7. Curso de Farmácia - JOÃO PESSOA } \\
\text { 8. Curso de Farmácia - RECIFE } \\
\text { 9. Faculdade de Farmácia e Bioquímica } \\
\text { - SALVADOR }\end{array}$ & $\begin{array}{l}\text { Universidade Federal do Maranhão } \\
\text { Universidade Federal do Ceará } \\
\text { Universidade Federal do R.G. do Norte } \\
\text { Universidade regional do Nordeste } \\
\text { Universidade Federal da Parába } \\
\text { Universidade Federal de Pernambuco }\end{array}$ & $\begin{array}{r}50 \\
100 \\
50 \\
80 \\
50 \\
80 \\
\\
120\end{array}$ \\
\hline TOTAL & & 530 \\
\hline
\end{tabular}

CENTRO-OESTE

10. Curso de Farmácia e Bioquímica CAMPO GRANDE

Universidade Federal de Mato Grosso do Sul 24

11. Faculdade de Farmácia - GOIÂNIA

Universidade Federal de Goiás

TOTAL SUDESTE

12. Curso de Farmácia BELO HORIZONTE

13. Escola de Farmácia - OURO PRETO

14. Curso de Farmácia - JUIZ DE FORA

15. Escolas de Farmácia e Odontologia de ALFENAS

16. Faculdade de Farmácia e Bioquímica do Espirito Santo - VITÓRIA

17. Curso de Farmácia RIO DE JANEIRO

18. Curso de Farmácia - NITERÓI

19. Curso de Farmácia RIO DE JANEIRO

20. Faculdade de Farmácia e Bioquímica - PRESIDENTE PRUDENTE

21. Curso de Ciências Farmacêuticas CAMPINAS

22. Curso de Farmácia e Bioquímica ARARAS

23. Faculdade de Ciências Farmacêuticas de RIBEIRĀO PRETO

Universidade Federal de Minas Gerais

niversidade Federal de Ouro Preto

Universidade Federal de Juiz de Fora

Isolada Federal

Estadual

Universidade Federal do Rio de Janeiro

Universidade Federal Fluminense

Faculdade de Ciências da Saưde Grande Rio

Associação Prudentina de Educação e Cultura - APEC

Pontificia Universidade Católica de Campinas $\quad 100$

Faculdade de Ciências Biológicas de Araras

Cadernos de Saúde Pública, R.J., 2 (4) : 511-532, cut/dez. 1986 


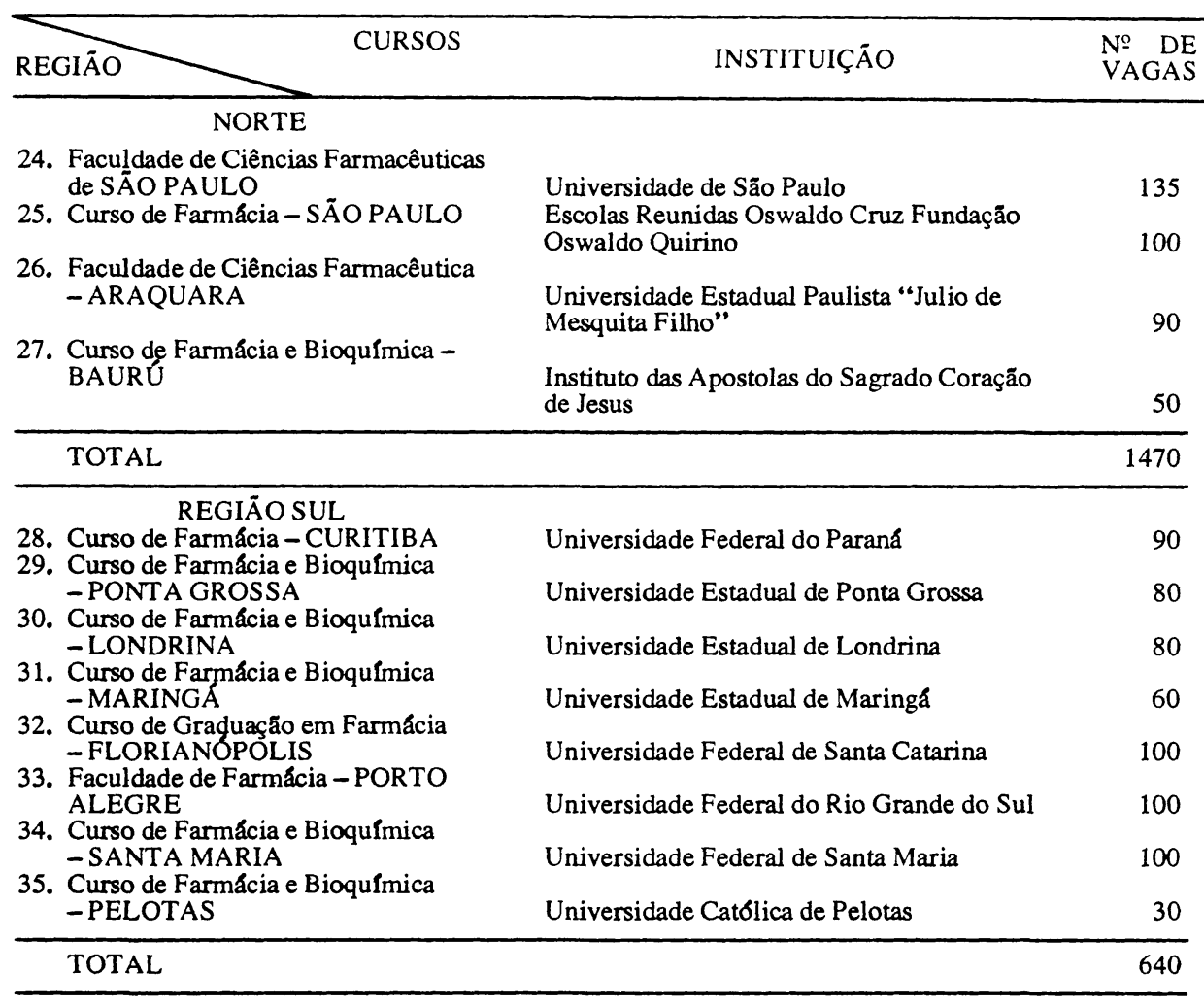

\section{TABELA II}

Número de Escolas ou Faculdades de Farmácia por Região com o respectivo número de vagas e percentuais

\begin{tabular}{|c|c|c|c|c|}
\hline \multirow{2}{*}{ REGIÃO } & \multicolumn{2}{|c|}{ NÚMERO DE ESCOLAS } & \multicolumn{2}{|c|}{ NÚMERO DE VAG } \\
\hline & ABSOLUTO & $\%$ & ABSOLUTO & $\%$ \\
\hline REGIÃO NORTE & 2 & 5,75 & 90 & 3.14 \\
\hline REGIÃO NORDESTE & 7 & 20,00 & 530 & 18.73 \\
\hline REGIÃO CENTRO-OESTE & 2 & 5,75 & 114 & 3.97 \\
\hline REGIÃO SUDESTE & 16 & 45,65 & 1.470 & 51.51 \\
\hline REGIÃO SUL & 8 & 22,85 & 645 & 22.65 \\
\hline TOTAL & 35 & 100,00 & 2.859 & 100.00 \\
\hline
\end{tabular}

Com relação à procura da Farmácia como carreira pelos jovens, continua sendo relativamente alta. Segundo dados da SEEC/MEC, no Vestibular do 10 Semestre de 1984, 17.193 
candidatos apresentaram-se para disputar 1.964 vagas, o que aponta 8,76 candidatos por vaga. Neste perfodo (1\% Semestre de 1984) o número total de alunos matriculados era de 13.369. Já o número de concluintes (1983) foi de 2.547 .

\section{TABELA III}

Número Percentual de Instituições de Ensino Farmacêutico por Subordinação Administrativo-Financeira

\begin{tabular}{lcc}
\hline SUBORDINAÇĀO & NÚMERO ABSOLUTO & PERCENTUAL \\
ADMINISTRATIVO-FINANCEIRA & 20 & $57.15 \%$ \\
\hline FEDERAL & 7 & $20 \%$ \\
\hline ESTADUAL & 1 & $2.85 \%$ \\
\hline MUNICIPAL & 7 & $20 \%$ \\
\hline PARTICULAR & 35 & $100 \%$ \\
\hline
\end{tabular}

Embora não se disponha de dados atualizados, tudo leva a crer que a constatação feita no estudo - "O ENSINO DA CIÊNCIA FARMACÊUTICA NO BRASIL"4 - Análise e Recomendaçōes de 1974, ainda continuam válidos. Neste trabalho, o que estudou exaustivamente a questão foi verificado que apenas $4 \%$ do alunado faziam opçâo por farmácia, $82 \%$ pelo setor de análises clínicas e toxicológicas e 14\% pela área de tecnologia.

Vários fatores contribuíram para esta situação que teve um saldo negativo para a profissão e para a saúde da população.

\section{O IMPACTO DA CRISE ECONÔMICA SOBRE O ENSINO DE FARMÁCIA}

A Economia tem um impacto muito elevado sobre a qualidade e a quantidade dos programas de ensino oferecidos. No Brasil, o grande período recessivo gerou sérias conseqüências sobre $o$ assunto em geral.

No caso específico da Farmácia, onde a maioria das escolas ou faculdades é dependente de recursos federais, os problemas gerados foram grandes em todos os setores.

ÁREA FÍSICA e EQUIPAMENTOS - A grande maioria das escolas de Farmácia se ressente de equipamentos, (e até mesmo reagentes e vidraria) para oferecer um ensino de bom nível. Os equipamentos são obsoletos e carecem de manutenção, por falta de recursos, aguardam anos para sua recuperação.

O CORPO DOCENTE - No Brasil sempre houve escassez de verdadeiros cientistas farmacêuticos, quer a nfvel de instituiçōes de ensino quer a nível de indústria farmacếutica. Este fato é agravado pelo pequeno número de cursos de Pós-gra- 
duação no país (apenas 8) (Tabela IV) e a pouca saída de profissionais para capacitação no exterior.

Enfrenta-se também a concorrência com a Indústria farmacêutica para a obtenção de pessoal qualificado. Com recursos limitados, a Universidade como um todo, enfrenta problemas sérios para manter seus docentes mais qualificados ou investir na contratação e formação de novos professores. Consideramos estratégica a questão do preparo de docente. Há necessidade de se buscar alternativas para o traçado de um programa nacional de capacitação de docentes na área de Farmácia (fármaco-medicamento), como forma de atualizar e modernizar o ensino de farmácia, hoje com um atraso de cerca de 20 anos em relação ao ensino de países mais desenvolvidos. É imperiosamente urgente a implementação do ensino da farmacocinética, biofarmácia, farmácia hospitalar, farmácia clínica, administração farmacêutica, saúde pública, fisiopatologia apenas para citar algumas disciplinas. Ainda no que diz respeito a docentes, é importante se pensar em cursos de educação continuada, como forma de manter a qualidade do ensino.

Reiteramos mais uma vez a necessidade de se estruturar programas de formação de docentes para nossas escolas. Esta ênfase é devida a importância definitiva para o futuro das Escolas ou Faculdades de Farmácia em nosso país. Os professores necessitam manter sua capacidade no manejo de novos e complexos equipamentos, necessitam que suas próprias atividades não sofram uma defasagem no contexto do mundo científico e tecnológico moderno, sem deixar de ser sensíveis a natureza mutante da prestação de serviços de saúde e ao papel a ser desempenhado pelos farmacêuticos, nestas mudanças.

AS BIBLIOTECAS - Como regra geral podemos afirmar que as escolas de farmácia são extremamente pobres em bibliografias específicas. Tomando como exemplo a farmácia hospitalar, inexistem textos nacionais bem como estrangeiros. Bibliografias para área de administração farmacêutica, farmácia clínica, biofarmácia, farmacocinética clínica são praticamente inexistentes no país. Periódicos da área são pouco comuns. Acreditamos que no momento existem condições para se modernizar o acervo das bibliotecas de nossas escolas através do PROJETO BIBLOS, recentemente lançado pela SESU/MEC dentro do Programa Nova Universidade.

A PESQUISA - Poucas escolas de Farmácia do nosso pás desenvolvem pesquisas, e estas têm sofrido as conseqüências das limitações impostas pela crise financeira. Entretanto, as pesquisas nesta área são absolutamente vitais para se alcançar o objetivo de se proporcionar "Saúde para todos no ano 2000 ". Os produtos farmacêuticos continuam sendo o método mais barato de terapia sanitária, e os novos descobrimentos na pesquisa farmacêutica freqüentemente tem forte impacto em outras áreas.

A pesquisa na área de produtos naturais, num país com uma flora tão rica necessita ser fortalecida, como forma de se encontrar alternativas medicamentosas eficazes e de baixo custo para a população brasileira. 
Especial atenção deve ser dada a natureza interdisciplinar das atividades de pesquisa de nosso tempo, já que a maioria dos trabalhos é fruto da integração de recursos de diferentes disciplinas. É necessário motivar mais as escolas de Farmácia a desenvolverem trabalhos de investigaçōes, a exemplo das Faculdades de Farmácia das universisades federal do Rio Grande do Sul e da Pará́ba, esta através do seu Laboratório de Tecnologia Farmacêutica - L.T.F.

O CURRICULUM - O atual curriculum mínimo de Farmácia, estabelecido pela Resolução no 4/69 do Conselho Federal de Educação $^{3}$, deixa claro o caráter multidisciplinar destes cursos, possibilitando aos farmacêuticos diferentes campos de atuação. Nas escolas de Farmácia são formados profissionais com títulos diferentes:

- Farmacêutico

- Farmacêutico Industrial

- Farmacêutico Bioquímico com 2 opções

I - Tecnologia de alimentos

II - Análises clínicas e toxicológicas

Esta reforma curricular surgiu em meio a uma crise institucional do ensino quando até mesmo a extinção dos Cursos de Farmácia chegou a ser proposta. Essa crise teve por fundamento, em realidade, o fosso existente entre o ensino e a realidade de saúde do povo brasileiro. O acordo MEC/USAID, que dá causa à reforma do ensino é a gênesis dos descaminhos subseqüentes. É importante analisar os antecedentes históricos gerados da crise que culminou com o currículo vigente. Segundo o Professor José Aleixo Prates e Silva "esta reforma, longe de oferecer soluçōes adequadas à qualificação de profissionais para dispensação sob uma btica moderna, evidenciou manifesta substima a esse campo de atividade por excelência do farmacêutico, preferindo, antes, oferecer mais e melhores perspectivas para o ensino das Análises Clínicas e Toxicologicas. .."10

Até 1930 os procesos industriais estavam limitados a manipulação de produtos (vegetais e minerais) tendo como sede a "botica" ou pequenos estabelecimentos industriais. Os medicamentos aqui produzidos não se diferenciavam dos demais produzidos na Europa ou EEUU. Nesta época os americanos como europeus se preocupavam em constituir unidades de investigação científica o que não ocorreu aqui.

As pesquisas desenvolvidas culminaram com a descoberta de novos produtos dentre os quais se pode destacar: Vitamina $\mathrm{B}_{1}$, Sulfas, Hormônios, Antimicrobianos, Reserpina, Dexametasona, etc.

Estes produtos começaram a entrar no Brasil através das casas representativas, com objetivos comerciais: $O$ desenvolvimento tecnológico surgido após a Segunda Guerra Mundial, levou a que a pesquisa cientifica se transformasse em fonte de lucro industrial ao mesmo tempo que proporciona o aparecimento de novos produtos, gerando monopolios e lucros fantásticos para as empresas. Isto culminou com uma elevada concentração econômica e a oligopolização do mercado. 
As pequenas empresas nacionais, sem condições de acompanhar a evolução tecnológica ficam à mercê da entrada no Brasil, destas empresas econômicas e financeiramente fortes, ocorrendo daí o fenômeno da "desnacionalização". Esta entrada maciça de capital estrangeiro no setor farmacêutico, provoca, a nível de oferta, uma aproximação do mercao nacional ao mundial.

Os grandes laboratórios estrangeiros aqui instalados assumem progressivamente o controle da produção farmacêutica no Brasil, implantando novas fábricas, adquirindo laboratórios nacionais e assumindo o controle de outros.

O farmacêutico, deslocado de sua atividade nobre de manipulação na farmácia, cercado por produtos industrializados que proliferam desordenadamente, e dos quais de pouco ou nada sabe, se sente desestimulado a continuar nessa atividade. A nível de indústria, suas funções também se limitam a "gerente de produção", posto que as pesquisas, a síntese das matérias-primas e a pesquisa tecnológica propriamente dita são feitas nas matrizes instaladas no exterior. Aqui são executadas apenas as operaçōes referentes às $3^{\mathrm{a}}$ e $4^{\mathrm{a}}$ fases ou seja, a $3^{\mathrm{a}}$ fase é basicamente de procedimentos físicos, (sem grande significado tecnológico) e a $4^{\mathrm{a}}$ - fase é a de comercialização e "marketing" dos produtos industrializados. Tenha-se presente, só para um referencial no tempo, que a $1^{\text {a }}$ regulamentação federal das atividades da indústria farmacêutica já estavam solidamente instaladas no Brasil.

Naquele momento de crise, entenderam as lideranças da profissão e as autoridades responsáveis pelo ensino superior, ser oportuna a revisão curricular com abertura de novas opções, do que resultou a Resolução $4 / 69$ C.F.E. ${ }^{3}$ O medicamento é relegado a um plano secundário, entendendo-se que profissionais de nível superior de curta duração poderiam assumir a direção das farmácias : dispensação que proliferam no país, fortemente supridas ue medicamentos sofisticados. Assim não ocorreu porque o profissional não se sentia capaz de assumir esta tarefa pela deficiência de conhecimentos de farmacologia, de saúde pública e de administração farmacêutica. Como esta é uma atividade privativa da profissão farmacêutica, alterou-se a legislação, a farmácia passou a ser também de propriedade de leigos, com a responsabilidade técnica do farmacêutico na qualidade de simples empregado. Isto acarretou prejuízos enormes para a profissão, mas sobretudo para a população que comprovadamente tem na farmácia o seu primeiro posto de socorro, e que vem sendo assistida por leigos sem nenhum conhecimento sobre o potencial dos produtos farmacêuticos modernos postos à comercialização. Não é o que ocorre nos países desenvolvidos, onde a farmácia é um estabelecimento profissional, diversamente do que ocorre no Brasil, onde a farmácia e a drogaria, são casas comerciais apenas.

Quanto ao ensino da habilitação industrial, apenas 14 das 35 escolas ou faculdades de farmácia oferecem esta habilitação tendo em vista um mercado de trabalho restrito, sendo 
que dessas 14, a maioria não conta com equipamentos e instalações adequadas.

Entretanto, as 35 instituições mantêm, habilitação em análises clínicas e toxicologicas.

$\mathrm{O}$ atual Curriculum de Farmácia vem sendo motivo de questionamento e análises, de forma sistemática, por profissionais e educadores, bem como a questão, dos seus títulos e sua duração. Estes problemas devem ser resolvidos com o objetivo de buscar uniformidade, mantendo, entretanto, possibilidades de inovação dentro de cada curso buscando atender as peculiaridades regionais. Ainda com relação ao "curriculum", questōes fundamentais que emergem em todas as discussões são:

- O fosso existente entre as disciplinas do ciclo básico e do profissional a comprometer o próprio perfil curricular;

- disciplinas clássicas no currículo de Farmácia como a Botânica e a Farmacognosia estão em franco abandono. É necessário retomá-las, fortalecê-las, como forma de implementar a pesquisa na área de produtos naturais. Recentemente tem se ressaltado a importância da botânica não apenas no conhecimento das plantas medicinais, mas em outros problemas relacionados com a saúde ambiental. Os novos conceitos de pisos bioclimáticos demonstram sua importância em epidemiologia, como ficou claramente demonstrado através dos trabalhos do Dr. Rioux do Departamento de Ecologia Médica e Patologia Parasitária da Faculdade de Medicina de Montpellier ${ }^{9}$.

Com base nos pisos bioclimáticos se estabeleceram relações entre a distribuição de Phlebotomos e focos epidemiologicos de Leishmaniose no Marrocos;

- A Farmacotécnica necessita urgentes transformaçöes quanto ao contéldo. Dentro das ciências farmacêuticas esta disciplina foi uma das que teve um desenvolvimento muito significativo nos últimos 15 anos;

- A Farmacologia e a Farmacodinâmica necessitam de cargas horárias condizentes com o peso de sua importância na formação dos farmacêuticos;

- A inclusão da disciplina de Saúde Pública e Farmacocinética não podem mais ser postergadas;

- Programas de Farmácia Hospitalar devem ser implantados, de forma séria e criteriosa objetivando dar resposta às necessidades dos pacientes e do hospital e tendo em vista o necessário exercício da farmácia clínica.

É vital que a profissão enfrente a questão da dispensação a nível de farmácia páblica ou comunitária com a responsabilidade que o assunto requer. Os fundamentos do ato profissional farmacêutico tem seus alicerces em três princípios básicos capazes de gerar novas possibilidades para a profissão: 
- Conhecimento efetivo do medicamento;

- O relacionamento com o usuário do medicamento;

- O relacionamento com os prescritores de medicamentos - os médicos.

Não há dúvida, de que a realidade primeira e primária, é o conhecimento amplo, profundo e atualizado dos medicamentos. Sem este conhecimento dos medicamentos, não há perspectivas possíveis para a profissão farmacêutica.

A segunda realidade (que conforma o ato da dispensação) é a relação farmacêutico/usuário de medicamento. Se no conhecimento profundo dos medicamentos repousa a base de novas perspectivas profissionais, esta segunda, é a peculiar, essencial, a que caracteriza "o que fazer do farmacêutico" (diferente em alguns aspectos da farmácia hospitalar).

$\mathrm{O}$ relacionamento com os prescritores de medicamentos, deve ser perseguido, porque neste elo surgem possibilidades inesgotáveis de novas perspectivas profissionais, com benef1cios para ambas as categorias e maior segurança para o usuário do medicamento.

\section{OS FARMACÊUTICOS E SUA DISTRIBUIÇÃO NO TERRITÓRIO NACIONAL}

Segundo dados fornecidos pelo Conselho Federal de Farmácia (CFF) em 1985 estavam registrados nos Conselhos Regionais de Farmácia (CRFs) 31.272 profissionais farmacêuticos em todo o território nacional. Considerando a população geral de 124.128.374 habitantes a relação de farmacêuticos por habitantes é de 1: 3.969 habitantes.

No tocante à área física, a relação de farmacêuticos por $\mathrm{Km}^{2}$ é de 1: $270 \mathrm{Km}^{2}$.

Não dispomos, no momento de dados relativos ao número de farmacêuticos que exercem atividades junto à farmácia de dispensação e hospitalar, drogarias, laboratórios de análises clínicas e indústria farmacêutica.

\section{A EVOLUÇÃO DAS CIÊNCIAS FARMACÊUTICAS}

$O$ estudo da evolução das ciências farmacêuticas requ:r que se estude os fatores que incidem sobre ela e acompanhar como o sistema de conhecimentos "Farmácia" evolui de acordo com a evolução destes fatores. Os mais importantes e significativos são:

-A inovação farmacoterapêutica;

- Modificações legais na área do medicamento e a situação atual no Brasil;

- Modificaçōes no sistema de saúde - propostas atuais;

- A política industrial químico-farmacêutica.

A indústria farmacêutica atual teve suas bases no século passado. Pasteur, com sua teoria dos germes e sua compreensão básica da imunologia, conduziu as bases da indústria como a conhecemos hoje. Ao identificar um agente causal para uma infecção específica, coloc $\mathrm{m}$ cena os mecanismos para controlá-la. Posteriormente, a eoria de Ehrlich sobre a "bala mágica" que mataria os germes sem causar danos ao hospe- 
deiro, também foi fundamental. A descoberta das bases quimicas do controle do sistema nervoso autônomo responsável pelas funçōes automáticas do organismo tais como a digestão e a respiração por Barger e Dale trouxeram uma contribuição valiosa. Quando se verificou que determinados produtos poderiam produzir falhas sobre estes sistemas, estavam lançadas as bases para o desenvolvimento de produtos bioquímicos e medicamentos que corrigiriam tais defeitos. Estas descobertas conduzem ao aparecimento de medicamentos que passaram a atuar a nível de tecidos ou a nível intercelular, que trouxe, como conseqüência uma inovação farmacêutica espetacular, tornando realidade o sonho da "bala mágica" de Ehrlich por volta de 1930 , com a descoberta do primeiro antibacteriano, o Prontosil. Como conseqüência, nos anos quarenta e seguintes, apareceram a penicilina, os antibióticos de amplo aspecto, os anti-hipertensivos, os psicotrópicos, mais tarde os antiinflamatórios e os betabloqueadores para as doenças cardiovasculares.

Toda esta revolução terapêutica afetou de forma considerável a prática médica e farmacêutica. Os êxitos das pesquisas efetuadas pelos laboratórios farmacêuticos se traduziram em medicamentos que permitiram aos médicos salvar, prolongar e melhorar a vida de milhões de pessoas no mundo inteiro.

Rapidamente se evidenciou que o sucesso comercial da indústria farmacêutica significava que os conhecimentos eram cada vez melhores. Porém, trabalhar nas fronteiras da ciência tem seu preço. Após a tragédia da talidomida no início dos anos sessenta, os Governos começaram a regulamentar com mais rigor a produção e experimentação de novos medicamentos, fazendo pensar que dificilmente se conseguiriam grandes novas descobertas na área.

Indubitavelmente, uma reflexão mais profunda do tema, nos leva a cogitar que se as descobertas teóricas e doutrinárias do século XIX conduziram a esta primeira revolução farmacológica, as pesquisas e o desenvolvimento científico desta década que se iniciou com a descoberta e a pesquisa da estrutura do DNA por Watson-Crick em 1953, junto com os trabalhos de Biologia Molecular abrirão o caminho para o desenvolvimento da bioquímica intracelular e da segunda revolução farmacológica. Há três exemplos óbvios de doenças que provavelmente se beneficiarão com estas novas descobertas, as infecções víricas e já se conhecem agentes antivirais específicos tais como o ACICLOVIR bastante eficaz no herpes genital, o câncer ou doenças neoplásicas que como no caso dos vírus são processos que têm lugar no interior das células humanas. A compreensão desta bioquímica intracelular certamente conduzirá ao desenvolvimento de medicamentos ou métodos que previnam e controlem o crescimento das células cancerosas e é muito provável que estes novos agentes sejam menos tóxicos do que os atualmente conhecidos. No século XXI se desenvolverão métodos e medicamentos que nos permitirão a não mais considerar o câncer um flagelo, tal como no século passado se considerava a tuberculose. 
Outro grupo de doenças que certamente terão respostas são as chamadas auto-imunes, que ainda não estão identificadas e que são condições em que se desenvolvem os mecanismos de defesa do organismo que fogem ao controle e que ao invés de atacar microorganismos estranhos, se voltam contra os tecidos do proprio corpo. A complexidade deste processo ainda não está bem esclarecida mas e provável que muitas doenças como a esclerose múltipla, a doença de Parkinson, a artrite reumatoide possam ter origem desta forma.

$O$ desenvolvimento da engenharia genética e da genética molecular permitirão que doenças ligadas aos gens como a fenilcetonúria hoje tratada com dieta especial, no futuro será possível detectar, corrigir e até mesmo substituir os gens defeituosos. Além disso a bioquímica intercelular ou de tecidos terá grande desenvolvimento, de forma que áreas de pesquisa, que hoje já estão dando resultados práticos cresçam ainda mais e assim teremos as prostaglandinas, as encefalinas, as endorfinas que constituirão fantásticos avanços terapêuticos. A questão da liberação de medicamentos em quantidades adequadas para evitar que doses maciças circulem na corrente sanguínea, com os inconvenientes de reações adversas, modificarão o marco farmacoterapêutico existente hoje.

Esta análise do que poderá ocorrer no campo farmacoterapêutico nos leva a concluir que as inovações tecnolbgicas e pesquisas hoje realizadas darão lugar à segunda revolução farmacologica. Estes medicamentos serão muito mais específicos e portanto será necessário conhecê-los melhor para que possam causar os efeitos desejados. Se educar é uma atividade retrospectiva, pois formamos hoje para o amanhã, estes dados deverão ser necessariamente considerados desde agora quanto à modificaçăo do sistema de Farmácia para o futuro.

\section{ASPECTOS LEGAIS NA ÁREA DOS MEDICAMENTOS}

A questão do registro de medicamentos é uma das variáveis que devem ser mais seriamente avaliadas, pois influencia a prática da Farmácia. Fundamentalmente, pode-se dizer que existem três sistemas básicos de registro de medicamentos a saber:

- o de liberdade de registro no qual o Estado garante a segurança do fármaco;

- o Estado garante a eficácia do medicamento de acordo com as indicações do fabricante. Este tipo de registro existe na Suécia desde 1944 e foi adotado pelos EEUU como conseqüência da emenda Kefauer-Harris, A Food, Drugs and Cosmetic Act;

- o da exigência de eficácia relativa, isto $\hat{\text {, }}$ o medicamento a ser registrado deve ser mais eficaz que seus similares existentes no mercado. A Noruega é o único país que adota este sistema.

No Brasil, desde 1941, sempre houve um organismo oficial incumbido da fiscalização dos setores que interessavam à saúde pública. Inicialmente, apenas a Medicina foi objeto de atenção pois, na época, a produção de medicamentos ainda era ati- 
vidade artesanal. Criou-se então pelo Decreto-lei 3.171/41, o Serviço Nacional de Saúde. Em seguida, pela Lei 3.062/56, suas funções foram ampliadas, passando a chamar-se Serviço Nacional de Fiscalização de Medicina e Farmácia (SNFMF), subordinado ao Ministério da Saúde.

Pelo Decreto no 79.065 de 30.12.76, foi criada a Secretaria Nacional de Vigilância Sanitária (SNVS), que sucedeu ao antigo SNFMF, tendo como finalidade, de acordo com a Lei $\mathrm{n}^{\circ}$ 6.360, de 23.09.76 e esta, regulamentada pelo Decreto $\mathrm{n}$ 79.094 de 05.01.77, promover, elaborar, controlar, aplicar e fiscalizar as normas e padrões de vigilância sanitária.

Posteriormente, pela Portaria n 270-Bsb, de 10 de junho de 1978, do Ministério da Saúde aprovou-se o Regimento Interno da SNVS em cuja estrutura encontra-se a Divisão Nacional de Vigilância Sanitária de Medicamento, a DIMED.

Este órgão está revestido de dois poderes:

- o poder de homologar, que normaliza os procedimentos, através de decisões técnicas;

- o poder policial, que fiscaliza o cumprimento das técnicas do poder homologador.

Cada produto novo com registro concedido pela SNVS/DIMED/MS, significa que o governo garante a segurança do fármaco e dá seu aval a investimentos das empresas. O produto novo também cria concorrência a produtos antigos e, conforme sua origem, influi na balança comercial importação/exportação do país e, o que é principal, a liberação de um novo produto tem influência na dependência tecnológica do país. Portanto, o poder homologador, tem a possibilidade de direcionar o país para a independência ou para o colonialismo técnico.

No Brasil, o número de especialidades farmacêuticas licenciadas, nas suas diversas formas de apresentação, em oferta no mercado, tem sido objeto de grandes preocupações junto aos técnicos do setor. Segundo a DIMED, hoje, este número, bem como suas formas de apresentação, encontra-se por volta de 24.000 e 47.000, respectivamente. Comparando-se com outros países, como a França, Bélgica, Inglaterra e Espanha, vemos que enı média tais valores giram em torno de 3.500 e 11.000 , respectivamente, mostrando que grandes quantidades não refletem necessariamente que um País mantém um padrão de atendimento satisfatório.

A Organização Mundial de Saúde considera que pouco mais de 300 medicamentos atenderiam a exigência básica de qualquer país, bem como, recomendou aos países filiados a sua adoção. No Brasil a CEME elaborou a Relação de Medicamentos básicos que passou a chamar-se Relação de Medicamentos Essenciais - RENAME. Esta lista vem sendo constantemente aperfeiçoada e, hoje é composta de menos de 300 fármacos, atendendo perfeitamente as necessidades dos programas governamentais específicos do Ministério da Saúde (Tuberculose, Sáude Mental, Hanseníase, Câncer, Diabetes, Hipertensão, Imunização e Campanha de Saúde Pública) e a clientela previdenciária assistida pelo INAMPS e os Hospitais Universitários. 


\section{A REFORMA DO SISTEMA DE SAÚDE}

O Sistema Nacional de Saúde, instituído pela Lei 6.229 de julho de 1975, consolidou na prática a fragmentação do setor saúde, criando distorções enormes, com prejuízos para a população que em número significativo não tem acesso a nenhum serviço de saúde. Mesmo sendo o Brasil a $8^{\text {a }}$ economia do mundo nossos indicadores de saúde nos nivelam nesta área aos países menos desenvolvidos.

Das conclusões da VIII Conferência Nacional de Saúde, no TEMA 1 - Saúde como Direito, emergiu unânime a questão de que saúde $\varepsilon$ um direito de todos os cidadãos brasileiros e um dever do Estado.

No TEMA 2 - Reformulação do Sistema Nacional de Saúde, ficou explícito:

"A reestruturação do Sistema Nacional de Saúde deve resultar na criação de um Sistema Único de Saúde que efetivamente representa a Construção de um novo arcabouço institucional separando totalmente saúde de previdência através de uma ampla Reforma Sanitária".

Com relação ao novo Sistema Nacional de Saúde ficou expresso:

O novo Sistema de Saúde deverá reger-se pelos seguintes princípios:

a) referente à organização dos serviços:

- descentralização na gestão dos serviços;

- integralização das ações, superando a dicotomia preventivo-curativa;

- unidade na condução das políticas setoriais;

- regionalização e hierarquização das unidades prestadoras de serviços;

- participação da por lação, através de suas entidades representativas, na formulação da política, no planejamento, na execução e na avaliação das açōes de saúde;

- fortalecimento do papel do município;

- introdução de práticas alternativas de assistência à saúde no âmbito dos serviços de saúde, possibilitando ao usuário o direito democrático de escolher a terapêutica preferida.

b) atinentes às condições de acesso e qualidade:

- universalização em relação à cobertura populacional a começar pelas áreas carentes ou totalmente desassistidas;

- eqüidade em relação ao acesso dos que necessitam de atenção;

- atendimento oportuno segundo as necessidades;

- respeito à dignidade dos usuários por parte dos servidores e prestadores de serviços de saúde, como um claro dever e compromisso com a sua função pública; 
- atendimento de qualidade compativel com o estágio de desenvolvimento do conhecimento e com recursos disponíveis;

- direito de acompanhamento a doentes internados, especialmente crianças;

c) relacionados com a política de recursos humanos:

- remuneração condigna e isonomia salarial entre as mesmas categorias profissionais nos níveis federal, estadual e municipal, e estabelecimento urgente e imediato de plano de cargos e salários;

- capacitação e reciclagem permanentes;

- admissão através do concurso páblico;

- estabilidade no emprego;

- composição multiprofissional das equipes, considerando as necessidaes de demanda de atendimento de cada região e em consonância com os critérios estabelecidos pelos padrões mínimos de cobertura assistencial;

- compromissos dos servidores com os usuários;

- cumprimento da carga horária contratual e incentivo a dedicação exclusiva;

- direito à greve e sindicalização dos profissionais de saúde;

- formação dos profissionais de saúde integrada ao Sistema de Saude, regionalizado e hierarquizado;

- inclusão no currículo de ensino em saúde do conhecimento das práticas alternativas;

- incorporação dos agentes populares de saúde como pessoal remunerado, sob a coordenação do nivel local do Sistema Único de Saúde, para trabalhar em educação para a saúde e cuidados primários.

Como este novo Sistema de Saúde, descentralizado, regionalizado e hierarquizado afetará ou modificará o exercício da farmácia?

Julgamos que este momento é de extrema importância para o futuro da profissão farmacêutica. Devemos, todos unidos, aceitar este grande desafio de um profundo questionamento interno, para podermos dar respostas às necessidades da sociedade brasileira. Esta $\varepsilon$, na verdade, a hora de resgatar a imensa dívida que nossa profissão tem com o povo brasileiro.

\section{TENDÊNCIAS DA SOCIEDADE}

Após uma análise da evolução da Farmácia no tempo, no campo terapêtico, diante das modificaçōes do Sistema de Saúde, seria importante discutir alguns aspectos relativos à tendência da sociedade. $O$ que a sociedade exige dos farmacêuticos? Não resta dávida, que a sociedade cada vez quer saber mais, quer saber como se cuidar, e esta exigência trará como conseqüência, um aumento da automedicação. Neste aspecto, o farmacêutico tem um papel essencial a cumprir por

Cadernos de Saúde Pública, R.J., 2 (4): 511-532, out/dez, 1986 
ser o único elemento que vai servir de controle para um uso adequado dos medicamentos. $\mathrm{O}$ direito de saber, da comunidade explodirá, e a avidez de conhecimentos, a necessidade de saber, como usar adequadamente os medicamentos, para que servem, como atuam sobre sua doença, será cada dia mais uma exigência da sociedade. Este fato fará com que a Farmácia assuma um caráter cada vez mais clínico tanto em seu alcance como em sua função, modificando o papel tradicional do farmacêutico, de ser um dispensador de medicamentos para um "consultor de medicamentos", na medida em que os farmacêuticos ampliarem suas tarefas de dispensadores de medicamentos para uma implicação direta com o paciente. Estas novas funçōes exigirão um melhor preparo técnico dos profissionais.

É importante que os farmacêuticos estejam envolvidos no processo de planejamento deste objetivo, para que a sociedade possa se beneficiar de melhores serviços de saúde e da redução de custos resultante da otimização dos serviços farmacêuticos.

\section{A POLÍTICA NO SETOR QUÍMICO FARMACÊUTICO}

Neste setor de importância estratégica para o país, para a profissão farmacêutica e para a Segurança Nacional, foi apenas a partir de 1964/65 que efetivamente se instituíram mecanismos e instrumentos potencialmente capazes de induzir e incentivar o seu desenvolvimento.

O Decreto no 55.759 de 15.02 .65 estabeleceu estímulo ao desenvolvimento da indústria química em diferentes aspectos quer fiscal ou creditício. Entretanto as respostas obtidas não foram as esperadas.

A criação da Central de Medicamento/CEME em 25.06.71, pelo Decreto n 68.806 (modificado pelo Decreto $\mathrm{n}^{\circ}$ 69.451, de 01.11.71), como órgão vinculado à Presidência da República, representou um novo marco para o setor farmacéutico nacional, se bem que ainda com características exclusivas de instituição destinada a atuar na racionalização e no inventivo às atividades de pesquisa.

Com o advento do Decreto n- 71.205, de 04.10.72, a competência da CEME é estendida no sentido de incentivar a instalação no país de fábricas de matérias-primas necessárias a produção de medicamentos essenciais. Embora os instrumentos de apoio não ficassem explícitos o que se buscava era tentar garantir, pelo menos o mercado oficial de medicamentos aos projetos aprovados.

Assim, passou-se finalmente a estudar um modelo articulado de ação governamental, quer de especialidades farmacêuticas, quer de fármacos, permitiram determinar o campo de necessidades prioritárias de medicamentos e o grau de adequação dessas necessidades a uma oferta já fortemente condicionada pela ação do segmento empresarial multinacional.

Esse modelo ficou explicitado no Plano Diretor de Medicamentos integrado pelo conjunto de políticas e diretrizes que orientariam nẩo somente a demanda de medicamentos, como 
também, e de forma relevante, o sistema de oferta relacionando-o ainda ao desenvolvimento tecnologico da área.

Outro dos instrumentos estratégicos, e talvez, o de maior importância do Plano Diretor foi o estabelecimento e oficialização da Relação Nacional de Medicamentos Essenciais RENAME, que além de permitir concentrar a incidência do uso de medicamentos essenciais (importante fator de orientação do desenvolvimento industrial), possibilitaria também racionalizar a demanda governamental, de modo que o seu crescimento pudesse trazer comprometimentos ao balanço de pagamentos. Do conjunto de medicamentos essenciais brotaria o conjunto das matérias-primas prioritárias, cuja produção deveria ser estimulada.

Isso ficou expresso na Resolução CDI no 36, de 19.12.74, que estabelecia a política de incentivos a ser adotada para o setor químico-farmacêutico, que embora do ponto de vista quantitativo permanecessem os mesmos previstos no Decretolei $\mathrm{n}$ - 1.137/70, explicitava critérios qualitativos, bem como inseria a relação de matérias-primas farmacêuticas prioritánas extraídas da RENAME. Essa relação foi posteriormente revista e publicada através da portaria CDI n⿳ 408, de 04.09.75.

Tamberm a concentração da incidência do uso da demanda governamental, sobre a Previdência Social, permitiria a adoção de incentivo de garantia de mercado na primeira fase de desenvolvimento das unidades produtoras de materias-primas prioritárias.

Apesar do relativo desprestígio desse instrumento, conseguiu-se estimular empresários e pesquisadores nacionais para o estudo e produção de fármacos básicos, viabilizando alguns projetos importantes.

Conforme se verifica, a partir da instituição do Plano Diretor de Medicamentos e, por conseqüência, da RENAME e da Resolução CDI no 36/74, houve reversão tanto no número de projetos nacionais como no nível de investimentos por eles realizados que passaram a se tornar maioria. É bem verdade, que a pouca representatividade dos incentivos fiscais concedidos pelo CDI, a partir de 1977/78, levaram, principalmente as empresas estrangeiras, a investirem sem o beneplácito do CDI.

Como decorrência do explícito no próprio Decreto n72.552, de 30.7.73 (que previa em seu artigo 2 parágrafo único, item VII, alínea a), já se tentava desde o início de 1979, a retomada dos estudos para agregar os diversos órgãos envolvidos no setor, no sentido de instituir um órgão colegiado normativo e de coordenação setorial.

Tal providência só veio a ser concretizada com a criação da GIFAR em 23.10.81.

Por outro lado, em antecipação ao próprio GIFAR, a CE$\mathrm{ME}$, o CDI e BNDE, firmaram em 25.06.81 um Convênio para o estabelecimento de normas de atuação conjunta visando à implantação e ao desenvolvimento de indústrias sob controle de capital nacional, os primeiros resultados na área industrial estão produzidos em empreendimentos em sistema tripartite, tais como a Companhia Brasileira de antibióticos (CIBRAN), 
Guanabara Química Industrial S/A (GETEC), Bioquímica do Brasil S/A (Biobrás) e Insumos Químicos Farmacêuticos S/A (BIOFAR).

Vale acrescentar, no elenco de tais medidas, o constante do artigo 9 do Código de propriedade industrial que não considera privilegiável tudo quanto diga respeito a meios e processos para a obtenção de matérias-primas e produtos finais relativos a fármacos e medicamentos, um claro estímulo à técnica de copiação não apropriado adequadamente em nosso pais.

\section{O SETOR DE FARMÁCIA HOSPITALAR}

Existem hoje no Brasil um total de 5.854 hospitais com as seguintes características:

a) Quanto ao porte:

\begin{tabular}{ccc}
\hline PORTE & № & $\%$ \\
\hline Pequeno & 3.424 & $58 \%$ \\
\hline Médio & 1.642 & $28 \%$ \\
\hline Grande & 788 & $13,5 \%$ \\
\hline Total & 5.854 & $100 \%$ \\
\hline
\end{tabular}

b) Quanto a dependência administrativa financeira:

\begin{tabular}{ccc}
\hline ENT. MANT. & No & $\%$ \\
\hline Públicos & 1.348 & $23 \%$ \\
\hline Privados & 4.506 & $77 \%$ \\
\hline TOTAL & 5.854 & $100 \%$ \\
\hline
\end{tabular}

c) Quanto a entidade mantenedora:

\begin{tabular}{ccc}
\hline INST. & № & $\%$ \\
\hline Federais & 293 & 5.00 \\
\hline Estaduais & 704 & 12.03 \\
\hline Municipais & 305 & 5.22 \\
\hline Privados & 4.506 & 76.97 \\
\hline Total & 5.854 & 99.22 \\
\hline Cadernos de Saúde Pública, R.J., 2 (4): 511-532, out/dez, 1986
\end{tabular}


d) Quanto a localização:

\begin{tabular}{ccc}
\hline LOCAL & № & $\%$ \\
\hline Capital & 1.199 & $20.5 \%$ \\
\hline Interior & 4.685 & $79.5 \%$ \\
\hline TOTAL & 5.854 & $100 \%$ \\
\hline
\end{tabular}

Estes dados, considerando apenas os hospitais de médio e de grande porte, apontam uma necessidade imediata de cerca de 2.000 farmacêuticos hospitalares devidamente preparados para assumirem as complexas tarefas que a moderna farmácia hospitalar comporta. Este é outro dos grandes desafios que a profíssão como um todo deve enfrentar. Existem inámeros obstáculos, iniciando com o número insignificante de escolas de Farmácia que ministram ensino de farmácia hospitalar ainda de forma precária por não contarem com estágios estruturados com base na articulação com os serviços. A nível de especialização apenas 2 cursos são oferecidos, um junto ao Hospital Universitário da UFRJ, cuja clientela é constiturda basicamente de farmacêuticos que atuam em farmácias de hospitais de ensino. O outro curso, coordenado pelo Projeto de Capacitação de Recursos Humanos para o Controle da Infecção Hospitalar do Ministério da Saúde é realizado junto ao serviço de farmácia do Hospital Universitário Onofre Lopes da UFRN. Destina-se a farmacêuticos que já atuam em hospitais. Somadas as capacidades dos 2 cursos, são treinados por ano 30 farmacêuticos, muito pouco para quem necessita 2.000.

Neste sentido, buscando capacitar um contingente maior destes profissionais, o Projeto de Capacitação de Recursos Humanos para o controle de Infecção Hospitalar, submeterá a apreciação do Ministério da Educação e da Previdência e Assistência Social um Projeto Interministerial, propondo a escolha de 05 centros de treinamento na área, como forma de capacitar 100 farmacêuticos anualmente, entretanto, estas medidas ainda são insuficientes; é necessário que as Associações Profissionais se associem a este esforço.

O serviço de farmácia hospitalar teve e está tendo um significativo e promissor desenvolvimento, depois de reconhecida sua importância estratégica. As mudanças ocorrem celeremente, os sistemas de gestão utilizam modernas técnicas de administração. $O$ sistema de distribuição de medicamentos tem evoluído rumo à distribuição por dose unitária como forma de diminuir os erros de medicação e garantir ao paciente a melhor terapêutica a um menor custo. É necessário que os farmacêuticos hospitalares com o respaldo do conhecimento profundo e atualizado do medicamento, caminhem firme rumo à cabeceira do paciente. $O$ medicamento passou de uma dimensão técnica para uma dimensão clínica, e a Farmácia segue com ele. A Farmácia Clínica é um conceito ou uma filosofia, 
que dá ênfase ao uso seguro e apropriado dos medicamentos no paciente. Refere-se àquelas atividades farmacêuticas que se relacionam com o paciente ou estão orientadas para ele. $\mathrm{O}$ ponto central na prestação de cuidados de saúde é o paciente, portanto a qualidade do resultado dos cuidados implica no diálogo e interações entre os profissionais que prestam cuidados de saúde, e o paciente. No Brasil há apenas uma experiência de Farmácia Clínica da UFRN. É necessário cultivá-la com carinho para que sirva de modelo ao resto do país, e com a urgência necessária.

A Farmácia Clínica é um processo orientado para o serviço e somente será eficaz com sua utilização e consecução traduzido em um resultado positivo para o paciente. Algumas das atividades de Farmácia Clínica podem ser assim descritas.

1 - Desenvolvimento e manutenção de dados sobre medicamentos;

2 - Avaliação e revisão dos perfis medicamentosos do paciente;

3 - Desenvolvimento de critérios para assegurar as respostas do paciente ao tratamento medicamentoso;

4 - Comprovação das reações adversas ao medicamento e internações;

5 - Divulgação e fornecimento de informaçōes sobre o medicamento aos pacientes e outros profissionais da saúde;

6 - Cálculo de doses individualizadas usando princípios de farmacocinética;

7 - Participação na pesquisa clínica sobre medicamentos;

8 - Condução da revisão sobre o uso de medicamentos e o controle da terapia medicamentosa;

9 - Participação em outras atividades diretas de cuidados ao paciente;

10 - Detectar e corrigir incompatibilidades em misturas intravenosas de medicamentos;

11 - Informar aos pacientes subre o uso correto dos medicamentos com o objetivo de assegurar o cumprimento das ordens médicas proporcionar ao público educação sobre cuidados de saúde;

12 - Capacidade para avaliar a literatura sobre medicamentos e a forma correta de utilizá-la.

Eis um grande desafio para todos. Os obstáculos são grandes, mas não intransponíveis, na Capacitação Técnica estão as armas para enfrentar esse mais novo desafio.

A realidade de farmácia, conhecida como comercial ou de dispensação é trágica no Brasil, está ao abandono servindo apenas como postos de venda de medicamentos, e creio que todos os profissionais farmacêuticos envolvidos com mudanças, preocupados com a saúde da população sabem que $\varepsilon$ preciso mudar, que é necessário resgatar esta dívida com a população.

Esta farmácia, que prefiro chamar de comunitária tem que mudar de acordo com as tendências e as forças que vimos operar sobre o Sistema. Na proposta de modificação do Sistema Nacional de Saúde, regionalizado e hierarquizado vâo 
aparecer os postos de saúde e os centros de saúde. Como ficará a farmácia dentro deste esquema? Como atuará o farmacêutico no Centro de Saúde ou na Farmácia? É minha opiniāo que a Farmácia recomposta em suas funçōes de Serviço de Saúde integre efetivamente o Sistema e passe a ser de seus legítimos donos - os farmacêuticos. Quais funções poderiam os farmacêuticos realizar nestas farmácias, nos Centros ou nos Postos de Saúde? Creio que há muito a fazer, e para isso precisamos nos capacitar, pois não estamos preparados para executar todas as tarefas. Entre as funções assistenciais os farmacêuticos poderão efetuar ações direcionadas para:

- Farmácia clínica comunitária;

- prestar informação sobre medicamentos;

- executar tarefas de educação sanitária;

- desenvolver estudos epidemiológicos;

- desenvolver a formação e avaliação dos custos de assistência à Saúde do consumo e funções de fiscalização.

Cada um dos itens descritos comportam subitens. Por exemplo, na área de assistência temos funções de elaboração de critérios para a programação de medicamentos, elaboração de instrumentos para o acompanhamento da utilização de medicamentos e controle do tratamento medicamentoso aos pacientes crônicos (diabéticos, hipertensos, reumáticos, etc.) Estudos de farmacovigilância, história medicamentosa e controle de psicotropicos e entorpecentes.

$\mathrm{Na}$ área de informação de medicamentos, os farmacêuticos poderão atuar na elaboração de instrução farmacoterapêutica, informação técnica e científica sobre medicamentos ao pessoal das unidades básicas de saúde, orientação aos pacientes tratados nestas unidades de saúde sobre o uso racional de medicamentos.

$\mathrm{Na}$ área de educação sanitária, elaborar mensagens, textos, instruçōes, materiais audiovisuais para melhor utilização, administração, conservação e armazenamento dos medicamentos nas residências prevenindo acidentes e intoxicaçöes com crianças. Elaboração de instruções para gestantes sobre o uso de medicamentos na gravidez e na fase de amamentação. Elaborar instruçōes sobre práticas de higiêne em geral e contaminação ambiental. Educação para a população sobre o valor real dos medicamentos na recuperação da saúde.

$\mathrm{Na}$ parte de epidemiologia, podemos avaliar o consumo de medicamentos e sua relação com a morbidade e mortalidade na área de abrangência do serviço de saúde, estudos prospectivos e retrospectivos sobre reações adversas de medicamentos na população, estudos sobre iatrogenia, estudos comparativos sobre o consumo de diferentes medicamentos em regiōes de saúde equiparadas, etc.

Sem pretender esgotar o assunto, podemos ver que o farmacêutico comunitário pode realizar inúmeras funçōes de importância fundamental para a Sociedade, para as quais não há substituto. Neste momento em que grandes mudanças se avizinham, temos que ser ágeis, melhorar, evoluir, buscar uma 
capacitação adequada, adotar novos critérios, superá-los, e isto, em Gultima análise, é servir a sociedade.

A Farmácia é um sistema complexo, são muitas as forças que atuam sobre ela e é imprescindível que todas as ações sejam coordenadas e contem com o esforço de todos. Programas curriculares de graduação, programas de pós-graduação, associações profissionais, associações científicas. É necessário que as autoridades do país reconheçam o farmacêutico como um elemento da equipe de saúde, com um papel definido a cumprir e que a sociedade como um todo contribua exigindo destes profissionais os cuidados a que tem direito.

\section{BIBLIOGRAFIA CONSULTADA}

1. BRASIL. Ministério da Saúde. Cadastro de estabelecimentos de saúde: Brasil 1985. Braślia, 1985.

2. CONFERÊNCIA NACIONAL DE SAÚDE, 8ª Brasilia, 17-21 mar. 1986. Relatório final. Braślia, Ministério da Saúde, 1986. $21 \mathrm{p}$.

3. CONSELHO FEDERAL DE EDUCAÇÃO. Resolução no 4, de 11.04.1969. In: CURRfCULOS mínimos dos cursos de nível superior. 2. ed. Brasllia, MEC/DDD, 1975. p. 227-8.

4. CONSELHO FEDERAL DE FARMACIA. $O$ ensino das ciências farmacêuticas no Brasil: análise e recomendaçōes. São Paulo, Artpress, 1974.

5. CONSELHO NACIONAL DE PESQUISAS. Avaliação \& Perspectivas; farmácia e farmacologia. Brasnlia, 1982. v. 12.

6. INFORMATIVO do Conselho Federal de Farmácia, no 9. p. 7.

7. PHARMACISTS for the future: the report of the study comission on pharmacy. s.1., s. ed., 1975.

8. POURCHET-CAMPOS, M.A. O ensino farmacêutico em São Paulo. Såo Paulo, USP, 1949. p. 4.

9. RIOUX, J. A.; LANOTTE, G. \& RISPAIL, P. \& LEPART, J. Relations phlebotomes: bioclinnot en epidemiologie des leishmanioses, corrolaires epidemiologiques. L'exemple du Maroc. Pre-report of Medirerranean Bioclimatology Symposium. Montpellier, 1983.

10. SILVA, José Aleixo Pratis e. Farmácia hospitalar no Brasil: legislaçăo vigente, qualificaçăo profissional e mercado de trabalho. S.1., 1984 .

11. SMITH, G. T. The future for plarmaceuticals: the pattern and the problems. London, office of Health Economics, 1983. 